https://helda.helsinki.fi

\title{
Painful burning sensation on a tattoo during magnetic resonance imaging
}

\section{Kluger, Nicolas}

2019-04

Kluger , N , Brun-Leveque , P \& Gral , N 2019 , ' Painful burning sensation on a tattoo during magnetic resonance imaging ' , International Journal of Dermatology , vol. 58 , no. 4 , pp.

E82-E83 . https://doi.org/10.1111/ijd.14403

http://hdl.handle.net/10138/313691

https://doi.org/10.1111/ijd.14403

unspecified

publishedVersion

Downloaded from Helda, University of Helsinki institutional repository.

This is an electronic reprint of the original article.

This reprint may differ from the original in pagination and typographic detail.

Please cite the original version. 
Conflict of interest: None reported.

doi: $10.1111 / \mathrm{ijd} .14384$

\section{References}

1 Akhyani M, Hatami P, Yadegarfar Z, et al. Pigmented colloid milium associated with exogenous ochronosis in a farmer with long-term exposure to fertilizers. J Dermatol Case Rep 2015; 9: 42-45.

2 Siadat AH, Mokhtari F. Colloid milium. Adv Biomed Res 2013; 2: 28.

3 Gomes J, Ventura F, da Luz Duarte M, et al. Colloid milium successfully treated with MAL-PDT. Int J Dermatol 2013; 52: 767-769.

4 Amezcua S, López AM, Soria M, et al. Severe colloid milium presenting as papillomatosis cutis associated with vitiligo. Int $J$ Dermatol 2017; 56: 878-880.

5 Ghanadan A, Kamyab K, Daneshpajouh M, et al. Nodular colloid degeneration of the skin: report of three cases with review and update. Int Dermatol J 2014; 5: 36.

6 Li YL, Luo YJ, Wu Y, et al. Infrared-induced adult colloid milium treated with fractionated CO2laser. Dermatol Ther 2014; 27: 68-70.

7 Piccolo V, Russo T, Ossola M, et al. Colloid milium: the expanding spectrum of orange color at dermoscopy. Int $J$ Dermatol 2018; 57: e46-e48.

8 Martorell A, Balmer N, Sanmartin O, et al. Familial juvenile colloid milium: report of a well documented case. J Am Acad Dermatol 2011; 64: 203-206.

9 Azimi SZ, Zargari O, Rudolph RI. Nodular colloid milium mimicking keloid. J Cosmet Dermatol 2017; 16: e45-e47.

10 Mehregan D, Hooten J. Adult colloid milium: a case report and literature review. Int J Dermatol 2011; 50: 1531-1534.

11 Zeng YP, Nguyen GH, Fang K, et al. A split-face treatment of adult colloid milium using a non-ablative, 1550-nm, erbium-glass fractional laser. J Eur Acad Dermatol Venereol 2016; 30: 490491.

\section{Painful burning sensation on a tattoo during magnetic resonance imaging}

The occurrence of burning sensations on tattoos and permanent makeup during magnetic resonance imaging (MRI) has mainly been reported between the end of the 1990s and the mid2000s. ${ }^{1-5}$ However, large surveys performed in $2002^{6}$ and $2015^{7}$ support that such a side effect remains anecdotal. We report, however, a new case in a young woman with an old tattoo.

A 32-year-old woman presented for the removal of a dark blue tattoo on the right flank. It had been done by a beautician in southern Italy in 2009. The patient recalled that her tattoo was sometimes itchy and swollen with papules. After a traffic accident, she needed an MRI of the back and knee. Sixty seconds after the MRI was initiated, the patient felt tingling, stinging, and excruciating burning sensation on the tattoo. The pain level was evaluated retrospectively to be $10 / 10$ on a numeric scale. The symptoms disappeared when the procedure was stopped. A CT scan was performed instead without any complication. At presentation, the tattoo was unremarkable (Fig. 1). Upon request, test session $\left(3 \mathrm{~J} / \mathrm{cm}^{2}\right)$ triggered local erythema, itch, and headaches. Erythema subsided 3 weeks after with corticosteroids (Fig. 2). $\mathrm{CO}_{2}$ laser has been performed as replacement without further side effects.

We report a new case of burning sensation on a dark tattoo that led to MRI disruption. This side effect is currently known by radiologists but remains hopefully exceptional. ${ }^{1}$ To the best of our knowledge, the last cases were reported in $2011^{8}$ and 2012. ${ }^{9}$ Symptoms may range from slight tingling/stinging to burning sensation with warmth feeling and premature termination of the session. Transient local erythema and swelling may be observed. ${ }^{3,5,8,9}$ To date, only one case of second degree burn has been reported. ${ }^{4}$ Symptoms resolve without sequelae within a few hours to a few days. Tattoos are almost always dark colored. The tattoo design can be a fine lettering ${ }^{8}$ or plain patches. $^{4,9}$ Interestingly some authors stressed that tattoos applied with a loop pattern are most at risk for a cutaneous reaction. ${ }^{3,8}$ Our patient presented fine tattooed lines in various loops that suit previous observations.

The main hypothesis is that tattoos containing electrically conductive material, such as iron oxide pigments, may create during MRI an electric current that increases local temperature and may lead to a thermal cutaneous burn. ${ }^{8}$ Some authors recommend application of ice packs over tattoos during MRI. ${ }^{10} \mathrm{~A}$ Danish study recently challenged this hypothesis as the authors failed to find that tattoo inks underwent an increase of temperature to a relevant level during MRI. ${ }^{11}$ The symptoms may indicate possible involvement of the neuropathic pathway, such as transient receptor potential channels in the skin. ${ }^{11}$ However, the study was conducted in vitro in capped dishes. The possible interaction of MRI with tattoo ink in a biological skin sample and the role of loop patterns were not investigated.

In our case, we did not perform any biopsy to analyze the composition of the pigments. Q-Switched test was associated with an unexpected local reaction that prompted us to remove the tattoo with $\mathrm{CO}_{2}$ laser. As the tattoo was performed 9 years ago by a beautician, it is highly likely that the tattoo ink did not

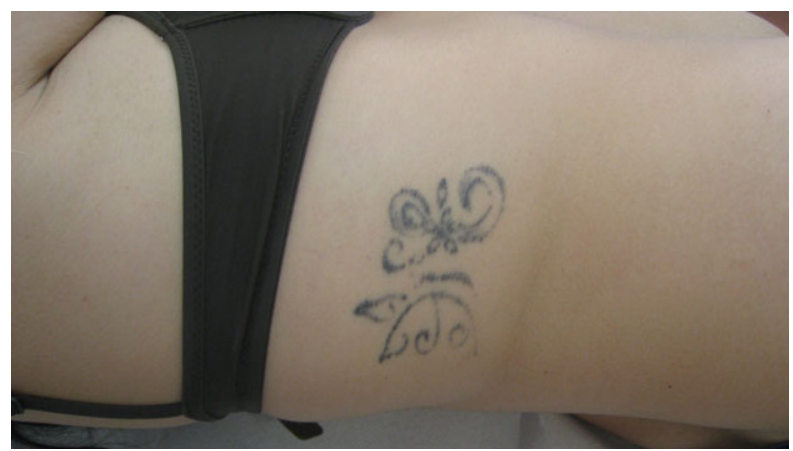

Figure 1 Nine-year-old dark tattoo of the right flank. The tattoo looks normal apart from color fading and poor aging probably due to low tattoo skills and poor ink quality 


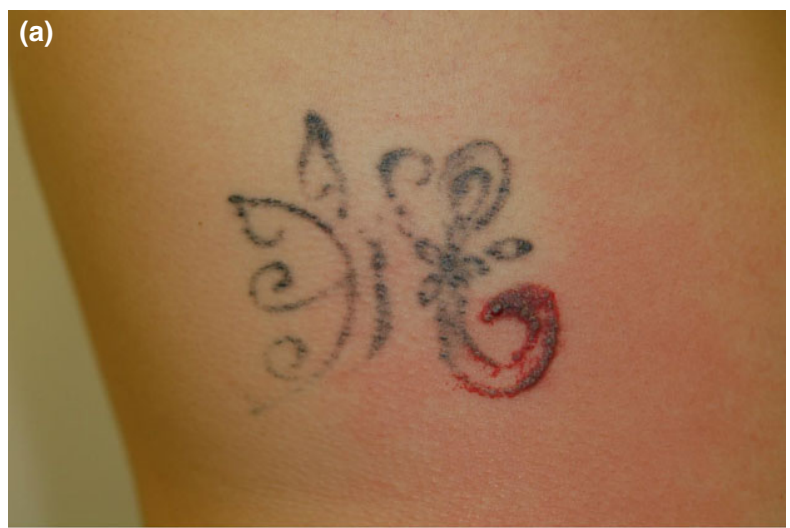

(b)

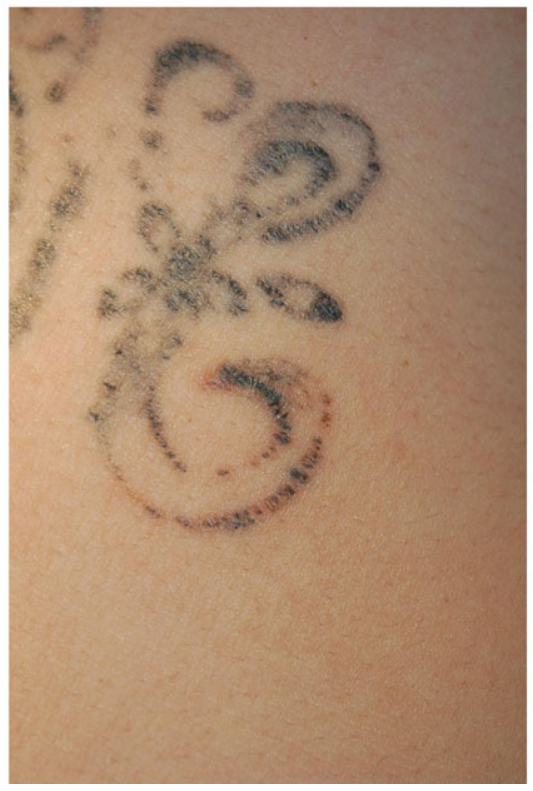

Figure 2 (a) Acute erythema in the vicinity of the Q-switched laser test. (b) Erythema subsided 3 weeks after application of betamethasone dipropionate ointment

respect the current recommendation of the Council of Europe published in February 2008 (ResAP(2008)1) and implemented by various European countries within the following years.

To conclude, MRI-induced burning sensations on tattoos are exceptional but can still happen. Screening forms should still carry a field for tattoos and patients be reminded about possible "heating" feeling of the tattoo. ${ }^{10}$ Caution is warranted with dark tattoos with loop patterns, especially those performed before 2009, in Europe especially.

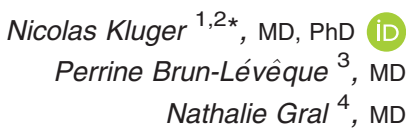

${ }^{1}$ Department of Skin and Allergic Diseases, Helsinki University Central Hospital, Helsinki, Finland

${ }^{2}$ «Tattoo» Consultation, Department of Dermatology,
Bichat-Claude Bernard Hospital, Assistance PubliqueHôpitaux de Paris, Paris, France

${ }^{3}$ Dermatology, Private Practice, Montbonnot-Saint-Martin,

France

${ }^{4}$ Dermatology, Private Practice, Grenoble, France ${ }^{*}$ E-mail: ${ }^{*} E-m a i l:$ nicolas.kluger@ hus.fi

Funding: None.

Conflicts of interest: None.

doi: $10.1111 / \mathrm{ijd} .14403$

\section{References}

1 Kluger N. Tattoos and medical imaging: issues and myths. Presse Med 2014; 43: 529-533.

2 Kreidstein ML, Giguere D, Freiberg A. MRI interaction with tattoo pigments: case report, pathophysiology, and management. Plast Reconstr Surg 1997; 99: 1717-1720.

3 Vahlensieck M. Tattoo-related cutaneous inflammation (burn grade I) in a mid-field MR scanner. Eur Radiol 2000; 10: 197.

4 Wagle WA, Smith M. Tattoo-induced skin burn during MR imaging. AJR Am J Roentgenol 2000; 174: 1795.

5 Franiel T, Schmidt S, Klingebiel R. First-degree burns on MRI due to nonferrous tattoos. AJR Am J Roentgenol 2006; 187: W556.

6 Tope WD, Shellock FG. Magnetic resonance imaging and permanent cosmetics(tattoos): survey of complications and adverse events. J Magn Reson Imaging 2002; 15: 180-184.

7 Noureddine Y, Bitz AK, Ladd ME, et al. Experience with magnetic resonance imaging of human subjects with passive implants and tattoos at $7 \mathrm{~T}$ : a retrospective study. MAGMA 2015; 28: 577-590.

8 Ross JR, Matava MJ. Tattoo-induced skin "burn" during magnetic resonance imaging in a professional football player: a case report. Sports Health 2011; 3: 431-434.

9 Kolnes K. Tattoo and MRI. Tidsskr Nor Laegeforen 2012; 132 : 1873.

10 Wang JF, Hindman NM. Prevention of thermal burns from magnetic resonance imaging in patients with tattoos. J Am Acad Dermatol 2018. [Epub ahead of print]. https://doi.org/10.1016/ j.jaad.2018.09.011

11 Alsing KK, Johannesen HH, Hvass Hansen R, et al. MR scanning, tattoo inks, and risk of thermal burn: an experimental study of iron oxide and organic pigments: effect on temperature and magnetic behavior referenced to chemical analysis. Skin Res Technol 2018; 24: 278-284.

\section{Ecthyma gangrenosum caused by Klebsiella pneumoniae and Streptococcus vestibularis in a patient with acute myeloid leukemia: an emerging pathogen}

Ecthyma gangrenosum (EG), a cutaneous infection most commonly associated with Pseudomonas bacteremia, usually occurs in immunocompromised patients. ${ }^{1}$ However, EG-like lesions have been observed in patients with other bacterial and fungal infections., ${ }^{2,3}$ Only three cases with Klebsiella pneumoniae have previously been reported to be a cause of EG. ${ }^{46}$ To our knowledge, no case of EG secondary to Streptococcus vestibularis has been reported in the literature so far. We 